\title{
The Adjustment of China's Regional Development Strategy and Its Impact on Intergovernmental Relations
}

\section{Indroduction}

Since 2008, many synthetically reform experimental districts have been set up, and a considerable number of local development planning has been promoted as national-level development strategies. This indicates some changes in the regional development strategy in China. The government has re-designed the regional development patterns and has decided on a regional development strategy based on more scientific national spatial planning. Moreover, the layout of regional development has become more detailed. At the same time, the state has encouraged the locals to develop their own characteristics according to their own advantages. By this way the state enriches the content of the national and regional development strategies. The adjustments in the national and regional development strategies have also led to changes in intergovernmental relations.

\section{The evolution of regional economic development strategy}

Since 1978 China's regional development pattern has been changing under the influence of uneven regional development; the regional development strategy has also been constantly adjusted.

The pattern of the regional development in China has experienced a lot of changes, including three zones (eastern, western and central), four plates (eastern, western, central and northeast)," three big regions and five small economic areas", "six core economic circles" and four main functional areas. The aims and purposes of regional division have also changed gradually.

\subsection{Three Regions}

In the 1980s, the concept of regions was embodied in the division of three regions: the eastern, the western and the central. The three regions became a basis of regional division of the national economic and social statistics. However, there were 
some problems with this kind of division. Firstly, the western region was too wide. The eastern part of Inner Mongolia was actually located in the northeast. Secondly, the scope of the central region was also too wide. It involved not only six provinces in the central part, but also three northeastern provinces. But these three provinces were not in the middle from a geographical point of view. The coastal areas of Liaoning actually belonged to the eastern coast. Thirdly, it had been quite a long time before the idea of three regions was proposed as a policy concept. For example, the eastern region had never been given a unified regional policy, and the general policies were formulated only for the coastal areas. In 1999, in order to narrow down the developmental gap between the eastern and western regions, the state put forward the Western Development Strategy (xi buda kaifa). The implementation of the Western Development Strategy was the beginning of policy implications in accord with the division of the three regions.

\subsection{Four Plates}

In 2002, the rate of economic growth of the western region exceeded that of the central region for the first time. This made the central region aware of the developmental crisis in the central region. In light of the problems of regional division, the state decided to separate the north-eastern region from the central one. Since then, the "three regions plus the northeast region" model has become the basis for regional development strategies and regional policymaking. In 2003, the strategy of revitalizing the old industrial base of the northeast was put forward. At the same time the central region also began to affect the decision-making of the central. In 2006, the state introduced the policy based on "a number of observations on the progress of the central region". Based on the spatial structure of the four plates, the national Eleventh Five-Year Planning proposed the following overall regional development strategy: "Adhere to the implementation of the western development, promote the old industrial base in northeast, boost the rising of the central region, encourage the northeast to lead the development and promote the interaction among east, central and west ,..

\section{Three Big Regions, Five Small Economic Areas and Six Core Eco- nomic Circles}

Along with the aggregation and dispersion of the regional development pattern, the regional development strategy in China is further refined. The three big regions are the ring of Bohai Sea, the Yangtze River Delta and the Pearl River Delta. The five small economic areas refer to the Liaoning coastal economic belt, Shandong of the Yellow River Delta Ecological Economic Zone, Jiangsu Coastal Economic Zone, the west side of the Taiwan Strait Economic Zone and the Guangxi 
Beibu Gulf Economic Zone. The six core economic zones (belt) include the capital economic circle, the circle of economy of the Bohai Sea Basin, the East China Sea economic circle, South China Sea economic circle, the upper reaches of the Yangtze River economic belt and the belt of economy of the middle reaches of the Yellow River.

There are some crossings among the three big regions, five small economic areas and six core economic circles. It's a common phenomenon that big economic circles trap small economic circles. For example, among the five small economic areas, the Liaoning coastal economic belt and Shandong Ecological Economic Zone of the Yellow River Delta are both located in the area of the Bohai Sea Basin, and the Jiangsu Coastal Economic Zone is located in the Yangtze River Delta region. This has formed a cross pattern. The crossing is also reflected in the distribution of the six core economic zones (belt): the capital economic circle and the economic Bohai Sea Basin have a cross, the East China Sea economic circle crosses the Yangtze River Delta and the west side of the Taiwan Strait Economic Zone, the South China Sea Economic Circle crosses the Pearl River Delta and the Beibu Gulf Economic Zone. The inland core economic zones take the Yangtze River Valley and the Yellow River Valley as the shaft, and they are all trans-provincial economic zones. The upper reaches of the Yangtze River Economic Belt is based on the Wuhan City Circle, the Changsha-Zhuzhou-Xiangtan City Group and the Chengyu area, while the middle reaches of the Yellow River Economic Belt rely on the Central Plains area, the Guanzhong area and the national energy base. The crossing provides multiple opportunities for areas located at the edge of these places.

\section{Four Kinds of Main-Function Zones}

At the end of 2010 the State Council promulgated the "national planning for main-functional zones". According to the capacity of resources and environment, the developing level and the potential of further development, the country is divided into four kinds of zones (zhuti gongneng qu): optimized development, key development, restrictive development and prohibitive development. According to the developmental criteria, the country is divided into city areas, agricultural areas and ecological areas. The main-functional zones are distributed as national and provincial. As the first nation-wide spatial plan in China, the four main-function zones emphasize that different regions should determine the functional orientation and development pattern according to the bearing capacity of resources and environment, so that they can control the intensity of development.

The four main-function zones planning is a kind of land planning, which is different from other regional divisions such as the "Three Regions" or "Four plates". Firstly, regional concepts like the "Three Regions" or "Four plates" 
considers a region as a comprehensive economic and social development unit, while the main-function zone considers a region as a territorial development unit. From the planning perspective, the planning of regional development focuses on the specific advantages in different areas. The goals of regional development and the regional layout are defined from the macro perspective. For example, the division of "Four Plates" is based on different development advantages of the four regions and highlights the characteristics of economic development in different regions. In contrast, national spatial planning takes the territorial development mode in order to focus and emphasize the environmental protection and sustainable development issues. The four different types of main function zones reflect the spatial regulation policy on territorial development, which are committed to guide the local and regional economic development.

Secondly, the division of the main-functional zones is based on whether it can be developed and on what depth it can be developed. It emphasizes sustainable development. But other regional divisions, like the "Three Regions", consider a region as the unit; the divisions are mainly based on the regional economic ties and the formation and likely improvements of regional competitiveness.

Thirdly, the division of the main-functional zones is based on the national perspective. It aims to achieve the goal of national and regional development layout and the balance of disparity in regional development. In contrast, other regional divisions are based on regional and local perspectives. Each area aims towards the goal of promoting regional economic development, which is likely to increase the developmental gap between regions. The main-functional zone division covers all the land, while only the "Three Regions" and "Four Plates" in former regional division covered the whole country. So it means that the regional development policy in China has changed from gradient development to balanced development. The territorial planning also asks every province to develop their own main-function zone planning, and it considers the county as the smallest planning unit. That means that the future of economic zone planning and development can only be based on the main-functional zones planning so that the development of local and national development is connected more closely.

\section{Changes of growth pole distribution}

The placement of China's growth pole has experienced the establishment of a developmental zone (Special Economic Zone), comprehensive reform test zone, special reform testing area, and regional planning which rises to the national development strategy. At the beginning of the reforms and opening up, the development in China concentrated in coastal and border areas, together with the regions along rivers (mainly the Yangtze River). The modes of opening and development are the establishment of special economic zones and various economic development 
zones. Actually, a development zone is a window and an example, which plays the function of a radiating and driving effect. The economic development zone is the first regional development mode since China's reforms and opening up. At present, there are more than 130 state-level development zones.

\subsection{National comprehensive reform test zone}

At the beginning of the reforms, economical reform was the main task. With the deepening of reform, more and more social and other problems appeared. Those problems couldn't be solved by any single economic reform. To meet the needs of an overall reform, the state made some adjustments to the regional economy development mode, and some comprehensive reform test zones appeared. Since June 21st 2005, the Pudong New Area was approved as the first comprehensive reform test zone. At present, there are 3 comprehensive reform test zones, and the two others are the Binhai New Area and Shenzhen Special Economic Zone. These areas attempt to reform on economic, administrative, financial management and some other systems. Having been given more policy support and powers, the comprehensive reform test zone is often referred to as the "new special zone". As a different mode of regional economic development distribution, the basic idea of the comprehensive reform test zone is still gradient development, in which the growth pole guides the development of other areas.

\subsection{Special Reform Testing Areas}

Facing problems like the transformation of the economic growth pattern, adjustment of industrial structure and changes in urban-rural relations led by urbanization, the central government tried to solve them separately. The state also faces the other problems, like the environmental pressures brought on by over-exploitation of resources and environmental degradation, excessive dependence on exports, and insufficient domestic demand. One strategy of the central government was to choose some special areas to test the solution of these problems. Since June 2007, the central government has approved a number of special reform testing areas, which focus on certain economic development issues and different themes of exploration and reform. Unlike the first two modes, each special reform testing area attempts to resolve several major problems. The problem-oriented testing area has become the third mode of regional distribution.

\subsection{Extension of national development strategy}

Recently local governments have actively sought to get their local development planning approved by the central government. As soon as the local development 
planning was approved, they received the appropriate authority and special policy from the central one. These efforts by the local government made the national development strategy extended. Since 2009, more than 30 regional plans have risen into the national development strategy. These regional plans cover most parts of China. At the national level, they are based on the overall national strategy. And they have been given different strategic objectives and positioning. Local regional planning that is raised into the national development strategies has become a new mode of regional development distribution, and has changed the pattern of the regional economic development in China. This is also an important measure to explore the coordinated regional development.

\section{The function of regional development strategy refined and increased}

The sudden increase of special reform testing areas and local planning rising into the national development strategy have solved the specific problems encountered in the economic development, such as the change in the pattern of economic growth and environmental protection. This has enriched the function of the regional development strategy. Most of the new special reform testing areas and local planning that were raised into the national development strategy are at or below the provincial level. This reflects the refinement of the regional development strategy in China

\subsection{The new structure of regional development}

Firstly, the regional planning focuses on the integrity of the layout. Specifically, the national regional planning and testing area gradually extended from the east and the south to the central, the west and the northeast. This indicates that the imbalanced development strategy has been gradually changed to the balanced development strategy. At the same time, while focusing on coastal distribution, the regional economic development strategy has begun to pay attention to the development of frontier areas; the development of marine economy has been raised into the national development. Moreover, spatial scales of specific regional planning has been narrowed and gradually extended to the provincial and intra-provincial level. Currently, the Four Plates have constructed pan-regional cooperation as well as a multi-level economic system, which consists of an economic circle, the coastal economic zone and national reform testing areas.

Secondly, urban agglomeration-based network is in formation. Regional planning that is raised into the national development strategies and the establishment of national reform testing area have changed the past practices (which rely solely on the centre for urban development), and have formed some regions led by the urban agglomeration. Urban agglomerations and the metropolitan area 
instead of the core cities have gradually dominated the development of the regional economy in China. At present, the urban agglomeration of the Yangtze River Delta, the Beijing and Tianjin city group, and the Pearl River Delta city groups are becoming the three urban agglomerations that lead the development of regional economics. In addition the Shandong peninsula, Liaoning south-middle, Middle Plains, the middle reaches of the Yangtze River, the west side of the Taiwan Strait, Sichuan and the Chongqing city group and Guanzhong-Tianshui urban agglomerations have also been formed. The Chang-Zhu-Tan city group, Wuhan Metropolitan Area and Wanjiang City Belt are all driven by urban agglomerations. Different economic circles and city belts are formed both vertically and horizontally, so they formed a new network pattern.

The third one is the plurality of distribution of the growth pole. Multiple regional growth poles with strong radiation power are becoming "engines" for regional economic growth. Since 2009, more than 10 regional plans have been approved by the state. The coastal economic belt of Jiangsu, coastal economic zone of Liaoning, Tumen river area, the west side of the Taiwan Strait Economic Zone and the Hengqin development zone are all introduced as inner-province planning. The reduction of the spatial scale is due to considerations about the strategic status of specific areas and they are all expected to be new sub-growth poles.

\subsection{Special Reform Testing Areas and Regional Development Planning}

The testing area and local planning that are raised into the regional strategy in China are all important measures for the national strategy. But there are some differences. National special reform testing area focuses on different topics such as the economic development pattern, the different topics of urban and rural development, construction of new industrialization and marine economic development. By innovating and exploring the systems and mechanisms, these areas are playing the role of a leader, header and model (Kong Jingyuan, 2008). Local planning that has been raised into the national strategy is aiming to adjust the economic layout, so that they can combine the "point" and "sphere" in the regional economy. The new growth pole will boost the development of the surrounding area, and also lead the nationwide development.

Those policies that support the special reform testing area and those that support the national regional development planning are also different. More specifically, the special reform testing area has received clear and specific national policy support, and it has been given the power of trial and error. For example, national development zones (like Pudong New Area, Binhai New Area, Chengdu-Chongqing Economic Zone and Chongqing Two Rivers Area) enjoy the most privileged policies. They have been given the power of trial and error in the fields of land, finance, taxation, investment as well as others. Moreover, the special reform testing areas are allowed to take measures that are more ground-breaking. These policies 
have attracted many foreign enterprises and large state-owned enterprises, and now they have become the driving force of economic growth in these areas. On the other hand, the driving force of the local planning comes from local innovation, and there are no more direct preferential policies from the central government. So the local governments have to use existing advantages or discover new strengths to explore new models of economic development. Local planning may have a leading role in the region, such as the Central Plains Economic Zone Development Planning, which mainly covers the Henan Province and then extends to the surrounding areas.

\subsection{Different functions between test area and local planning}

In recent years, there are more than 30 national experimental zones and regional plans that have been raised into the national strategy. "The state is vigorously pursuing economic zones and implementing the idea of "One Zone One policy". It has introduced a series of highly-targeted, pragmatic and operable regional planning and policy documents." (Fan Hengshan 2011, p. 4). Due to the different economic base, location, and resources, these regional planning and testing areas have been given different functions and positions.

One kind of the test area is to solve problems relating to development, which are subsequently outlined; 1 . solving the imbalance brought by the one-way economic development and exploring the coordinated road of economic and social development (Pudong New Area, Binhai New Area and Shenzhen Special Economic Zone), 2. exploring the balanced development (between urban and rural areas) model, and solving problems about urban-rural dual structure (ChengduChongqing), 3. solving the contradiction between economic development and environmental protection, and exploring sustainable development issues (the metropolitan area of Wuhan, Changsha, Zhuzhou and Xiangtan city group), 4. solving the industrial problem in traditional industrial areas and exploring the road of industrial transformation in old industrial bases (such as Shenyang Economic Zone), 5. solving the problem of environmental pollution and ecological destruction, and exploring the ecological model of economic development ("The Yellow River Delta efficient ecological economic zone development planning" and "The Poyang Lake Ecological Economic Zone Planning") (Fan Hengshan 2011, p. 6-7).

Another kind of the test area is to explore or promote new, development models, subsequently summarized by: 1 . promoting the industrial upgrading of the eastern coastal areas, taking the transfer of industrials to the central and the western regions (Wanjiang City Belt), 2. exploring the industrial restructuration in resource-based economies (the synthetically reform testing area of resources saving in Shanxi Province), 3. Exploring the transformation of trading modes to solve the foreign trade dependence in China and to make a new model of world trade (Yiwu international trade of comprehensive reform), 4. expanding the regional development layout and looking for a new economic growth pole in 
the development of marine economy (the establishment of the Shandong Peninsula Blue Economic Zone, Zhoushan Islands New Area, Zhejiang Ocean and the economic development demonstration area), 5. Expanding the opening-up ideas and exploring the sub-regional and international cooperation (Guangxi Beibu Gulf Economic Zone, the establishment of the Tumen River Development Zone), 6. promoting the cooperation between the mainland, Macao, Hong Kong and Taiwan are raised into the National Regional Development Strategy (Hengqin Economic Zone, Qianhai Economic Zone and the West side of Taiwan Strait), 7. exploring private investment and financing developments by establishing the Wenzhou special reform testing area (Fan Hengshan 2011, p. 5-6).

\section{Impact on the intergovernmental relations}

The adjustment of the regional economic development strategies affects the relationship between the central-local and local governments. Firstly, the locals selected by the central government are given more autonomy. In the adjustment of the regional economic development strategy, the central government is in a dominant position. Only when the regional development has a truly regional or global strategic significance can a regional development plan to be raised into the national strategy. Once approved by the central government, the regional government will often be given appropriate powers and special policies. These powers include the freedom to perform development planning based on their own advantages and to unleash local initiative and innovation in the implementation process.

Secondly, the boundaries of administrative divisions are broken. The main problem local developments have faced is that local competitions lead to repeat constructions and local protectionism. By raising the regional planning into the national strategic level, the situation of isolated development in local governments has changed. The local governments start to focus on inter-provincial development and intra-provincial regional development. The central government has established regional coordination mechanisms that make relationships among local governments more cooperative. Although this trend of cooperation is gradually expanding, we should still pay attention to avoiding a new vicious competition aimed at sneaking into the national planning.

\subsection{Local factors in the nation regional development strategy}

Through the way in which local development planning is raised into the national development strategy, the central government absorbs the ideas of local and regional governments to enrich the nation-wide regional development strategy. The strategy does not just formulate it at the national level. The influences of local factors in the nation-wide regional development strategy have been increasing. 
Firstly, it is a top-down mechanism of the national testing area selection. The special reform testing area is an area chosen by the central government from a comprehensive viewpoint. Based on the pilot project, the successful experience of the test will be promoted all over the country. Regardless of the special reform testing area or integrated synthetically reform-testing area, all of them are encouraged to be explorative and innovative. At the same time, it is required that the results of these reforms and tests should be copied to some extent. That means the choices of regions are to be based more on national needs and the generating way is mainly top-down.

Secondly, making the local development planning rise from the bottom-up into the national development strategy. Among more than 10 regional development plans that have been raised into national strategy recently, most of them are formulated based on the adjustment of the national development strategy. Since these local plans have undergone demonstrations and experiments, and have a driven and radiating effect on the overall national development, they are brought into the national strategy. Generally the way of generation tends to be bottom-up. The status, location and strategic needs largely determine whether it can be raised into national development strategies. It is this bottom-up approach that gives local governments the space of self-understanding and rational planning, and then they can set development goals according to the development.

\subsection{Spread of development pattern}

By imitating the establishment of the national economic development zone, local special reform testing areas begin to appear. This indicates that the test area pattern is beginning to spread down from the central to the local level. This proliferation occurs mainly on the provincial level. Since 2008, many provinces have established local special reform testing areas. The special economic zones and experimental zones set up by provincial governments have become a growth pole to a certain extent. They have played the function of "polarization" and "proliferation" as well as an exemplary and leading role for the economic development of a province.

\subsection{Extension of the relationship between local governments}

With the realization of inter- and intra-provincial cooperation, regional developments have broken barriers on administrative divisions. The relationship between local governments has also changed a lot. Firstly, cooperation has been more frequent than competition between local governments. On the national level, local governments share some common interests which make the cooperation possible. Secondly, there have been cross-border institutions that enjoy real powers. "Regional cooperation must have institutions based on administrative systems" 
(Chen Shengyong, Ma Bin 2004, p. 24-34). They often show their effectiveness in accord with the authority and policy support given by the state. Thirdly, the administrative level has been increased and compounded. Among the national testing areas, some are between the provincial and municipal level, but in terms of the administrative status of the leading cadres, there is no single type of practices and regulations. Some of them are in the sub-provincial level while some others are in the higher levels. National testing areas or inter-regional planning approved or established by the state have formed new executive authorities, which are not a corresponding administrative jurisdiction within the existing administrative levels, but a compound administrative jurisdiction.

Finally, there has been a commission and "transfer" phenomenon of administrative power between local governments. The transfer of administrative power refers to the process that local governments or departments hand over one or more kinds of power or some links to regional regulatory agencies to form a regional administrative power. This regional administrative power is based on the administrative agreement between local governments. Once the agreement has been reached or an appropriate agency has been established, there will be a new common power, which is beyond the boundaries of the local authority spaces. (Yang Long and Peng Yanqiang, 2004, p. 61-66). This power is generally performed by the coordinating agency in the regional cooperation, such as a variety of coordination committees. Local authorities should be subordinated to such regional powers.

\subsection{New political function of economic zones}

The regional economic development strategy has begun to consider the political factors in China. Development of cooperation within neighbouring countries and reunification of the motherland and national unity are becoming the tasks of regional economic development. This means that the emergence of new functional areas (or economic regions) have begun to assume political tasks. For example, Hengqin overall development planning, approved June 24, 2009, takes advantages of the position adjacent to Macau and plays the role of integration under "one country, two systems ". Also it promotes close co-operation among Guangdong and Macao, and it is beneficial to the economic diversification in Macao as well as the maintenance of its long-term prosperity and stability. The west side of Taiwan Strait Economic Zone is another highlight of the evolution of the regional economic development strategy in China. As part of the strategic planning to promote reunification of the motherland, the west side of Taiwan Strait Economic Zone is of great economic and political significance to strengthen the exchanges and cooperation between the mainland and Taiwan. The consideration of domestic politics aside, the regional economic development in China also combines international political cooperation and regional economic cooperation. 
The opening of the Guangxi Beibu Gulf is an important measure to enrich the content of the China,-ASEAN cooperation and to promote economic integration and resource sharing in Southeast Asia.

\section{Conclusion}

There have been new opportunities for local governments to raise the local planning into the national development strategies. Fighting for the resources generated by central government policies has become a new focus. At present, there is still a number of regional planning competing to be promoted to the national development strategies, and some pilot area programs have been in the approving process. This new trend of the regional development strategy in China deserves our continued attention.

\section{References}

Chen Shengyong, Ma Bin. (2004). "Cooperation between Regional Governments: Options of Regional Economic Integration”. CASS Journal of Political Science. 1: 24-34.

Fan Hengshan. (2011). "Theory and Practice of Promoting Coordinated Regional Development in China". Comparative Economic \& Social Systems. 6: 4-7.

Kong Jingyuan. (2008). National Development and Reform Commission of the People's Republic of China: The Director talks about reform online: about synthetically reform testing district. November 6, 2008. URL: <http://www.sdpc.gov.cn/tzgg/ggxsfx/t20081111_245515.htm> [accessed November 4, 2012].

Yang Long, Peng Yanqiang. (2009). "Understanding the Cooperation between Local Governments: From the Perspective of the Transferrance of Administrative Jurisdiction". CASS Journal of Political Science. 4: 61-66.

Wang Jiating. (2007). "Spatial diffusion mechanism of institutional innovation on national comprehensive reform testing area". Nanjian Social Science. 7: 39-44. Zhang Jingen. (2009). "From regional administration to regional governance: the trend of regional economic integration in China”. Scholar Research. 6: 42-48. 